\title{
A Case of Chronic Invasive Rhinocerebral Mucormycosis with Pott's Puffy Tumor
}

\author{
Chan Lee ${ }^{1}$, Sung-Eun Choi ${ }^{2}$, Hyung-Ju Cho ${ }^{1,3}$, and Jong-Gyun $\mathrm{Ha}^{1} \mathbb{D}$ \\ ${ }^{1}$ Departments of Otorhinolaryngology, ${ }^{2}$ Pathology, ${ }^{3}$ The Airway Mucus Institute, Yonsei University College of Medicine, Seoul, Korea
}

\author{
Pott's Puffy Tumor를 동반한 만성 침습적 비뇌모균증 1예 \\ 이 찬 $^{1} \cdot$ 최성은 $^{2} \cdot$ 조형주 $^{1,3} \cdot$ 하종균 $^{1}$ \\ 연세대학교 의과대학 이비인후과학교실, ${ }^{1}$ 병리학교실, ${ }^{2}$ 기도점액연구소 ${ }^{3}$
}

\author{
Received April 27, 2019 \\ Revised July 23, 2019 \\ Accepted August 7, 2019 \\ Address for correspondence \\ Jong-Gyun Ha, MD \\ Department of Otorhinolaryngology, \\ Yonsei University \\ College of Medicine, 50-1 Yonsei-ro, \\ Seodaemun-gu, Seoul 03722, Korea \\ Tel $+82-2-2228-3621$ \\ Fax $+82-2-393-0580$ \\ E-mailrhinohaj@yuhs.ac
}

Mucormycosis is one of the most fatal and rapidly progressive fungal infections in humans; among its many forms. rhinocerebral mucormycosis is the most common. It is known to occur as opportunistic infection in patients with uncontrolled diabetes, metabolic disorders, organ transplantation, or autoimmune disease with prolonged steroid use. Pott's puffy tumor is the subperiosteal abscess of the frontal bone caused by trauma complication or frontal sinusitis. It is considered as a very rare complication since the dawn of antibiotic treatments. We report a case of chronic rhinocerebral mucormycosis involving Pott's puffy tumor in a patient receiving immunosuppressive therapy after lung transplantation.

Korean J Otorhinolaryngol-Head Neck Surg 2020;63(8):375-80

Key Words Lung transplantation · Mucormycosis · Pott puffy tumor.

\section{서 론}

모균증(mucormycosis)은 인간에게 발생하는 진균 감염 중 가장 치명적이며 빠른 속도로 진행되는 질환으로 비뇌모 균증(rhinocerebral mucormycosis)이 가장 흔한 형태로 알 려져 있다. ${ }^{1,2)}$ 주로 조절되지 않는 당뇨, 대사장애, 장기이식 환자, 스테로이드를 장기간 사용한 자가면역질환 환자에게 서 기회감염으로 발생하며 국내에는 1980년대 이후 자가면 역질환 및 장기이식 환자가 늘어나게 되면서 장기간 면역억 제제 및 스테로이드 사용 증가로 발생률이 점차 늘어나는 추세이다. ${ }^{3-5)}$

Pott's puffy tumor(PPT)는 외상이나 전두동 부비동염의 합 병증으로 인한 전두골의 골막하 농양이며 항생제의 보급화 이 후 매우 드물게 일어나며 성인에게서는 더 희귀한 질병이다. 저

This is an Open Access article distributed under the terms of the Creative Commons Attribution Non-Commercial License (https://creativecommons.org/licenses/by-nc/4.0) which permits unrestricted non-commercial use, distribution, and reproduction in any medium, provided the original work is properly cited.
자들은 폐이식을 받은 후 면역억제제를 복용 중인 성인 환자 에서 만성적인 형태를 보이며 PPT를 동반한 비뇌모균증 1예 를 경험하였기에 문헌 고찰과 함께 보고하는 바이다(Fig. 1).

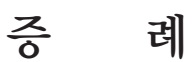

55세 여자 환자가 6개월 전부터 지속되는 좌측 안와 주위 부종과 동통으로 안과 진료 중, 4 개월 전부터 천천히 진행되 는 좌측 이마 $2 \mathrm{~cm}$ 크기의 돌출된 형태의 발적과 압통이 동 반된 종창으로 본과 외래 내원하였다(Fig. 2A). 환자는 고혈 압, 조절되지 않는 당뇨, 만성신부전의 과거력이 있었으며, 10 개월 전 폐 이식 후 면역억제제를 복용 중인 상태였다.

Lipoid pneumonia의 급성 악화로 응급으로 폐 이식을 받 은 환자였기에 폐 이식 전 paranasal sinus view는 시행하지 않았었으며 안와 주위 부종을 이유로 폐 이식 $4,6,10$ 개월 후 안과에서 시행한 caldwell view상 좌측 전두동의 가측 경계 경화 및 골파괴성 변화를 보이며 전두동이 확장되고 있 


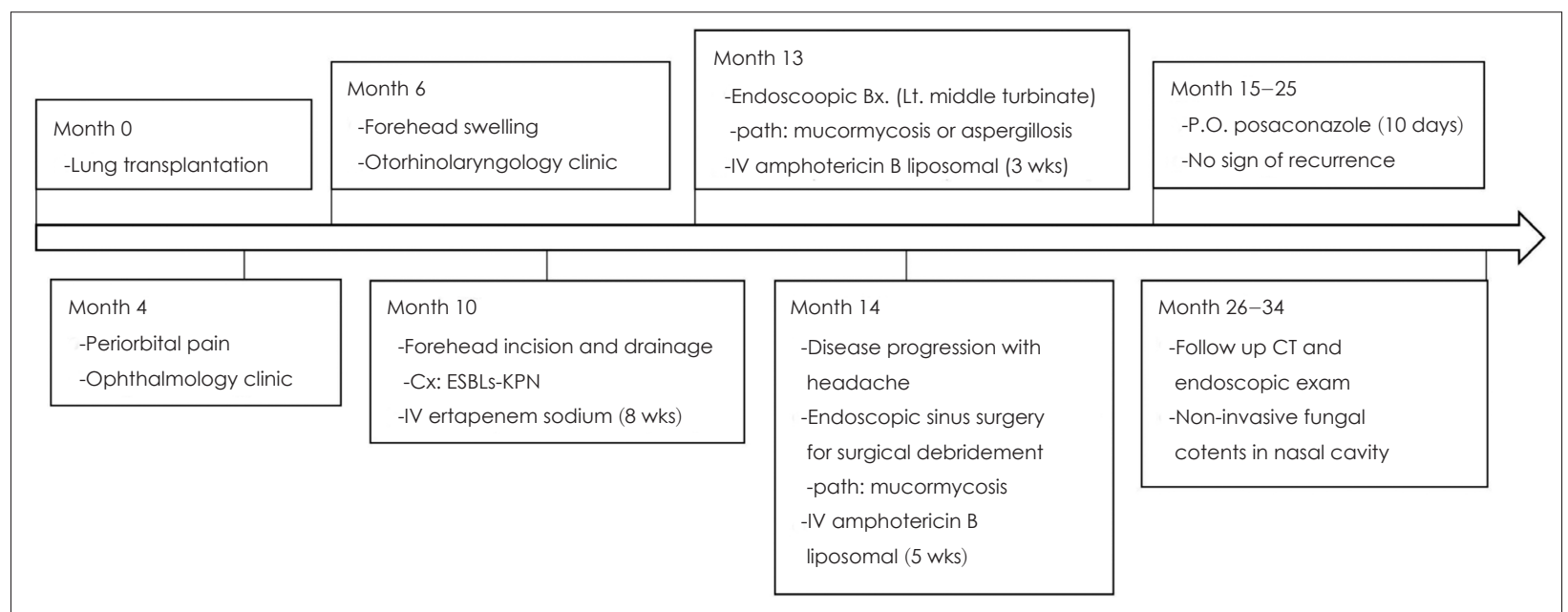

Fig. 1. Course of disease and treatment in chronological order. ESBLs-KPN: extended spectrum $\beta$-lactamase producing Klebsiella pneumoniae. Bx: biopsy, Cx: culture, P.O.: peroral.
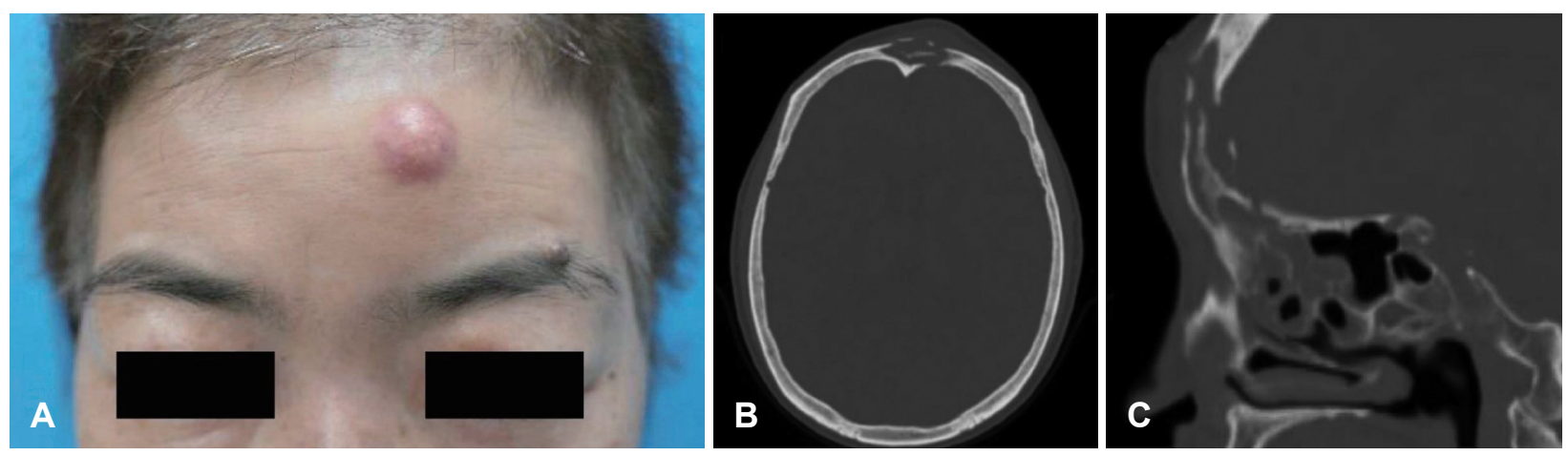

Fig. 2. Physical appearance and computed tomography (CT) of forehead and frontal sinus lesion. Facial photograph demonstrates swelling of left forehead and periorbital area (A). Orbit CT taken 6 months after lung transplantation shows frontal sinus lesion connected to external forehead swelling in axial (B), sagittal view (C).

었다. 비내시경검사상 비강 내 가피와 용종성 조직이 중비갑 개 주위에서 관찰되었다. Orbit computed tomography(CT) 상 이마의 종창과 이어진 전두동 내 병변 및 상안와벽의 결 손을 확인하였다(Fig. 2B and C).

좌측 이마 종창에 대하여 external eyebrow incision 접근 법을 이용한 배농 및 조직검사를 시행하였다. 병리 소견상 괴 사성 조직만 관찰되었으며 진균이 확인되지 않았다. 배양검 사 결과 extended spectrum $\beta$-lactamase producing Klebsiella pneumoniae가 동정되어 8주간의 IV ertapenem so$\operatorname{dium}(1 \mathrm{~g} /$ day $)$ 치료 후 환자 증상이 일부 호전되었다.

절개 및 배농 시행 3 개월 후, 외래 비내시경 소견상 중비 갑개로 추정되는 골 절편이 비강 내에 노출되어 조직검사를 진행한 결과 다수의 침습적 양상의 균사 소견을 보여 모균 증 또는 침습적 아스페르길루스증(aspergillosis)이 의심되 었다. CT에서 전두-안면부의 연조직 부종, 전두동 골파괴와 함께 내부 내용물의 석회화 소견을 보였다. 또한 MRI T1 강 조영상에서 저신호 강도, T2에서 불균질한 강도의 fungal ball로 의심되는 내용물이 관찰되었으며 직접적인 대뇌 침 습은 확인되지 않았으나 주변부로 고밀도 염증 소견이 확인 되었다. 해면정맥동 및 내경동맥 혈전증은 관찰되지 않았다 (Fig. 3).

침습성 진균성 부비동염 진단하에 수술을 계획하였으나 기저질환이 많고 만성적인 양상으로 환자 및 보호자가 거부 하였다. 이에 liposomal form의 IV amphotericin B(250 $\mathrm{mg} / \mathrm{day}$ ) 치료 시행 중 3주째 증상 악화 및 headache를 호소 하여 다시 설득 후 수술을 계획하였다. 수술 시 두개저 결손, 뇌척수액 유출을 우려하여 저자들은 우선 두개안면절제술 을 통한 광범위 제거를 고려하였다. 그러나 환자의 전신 상태 로 인해 회복이 어려울 것으로 판단하여 네비게이션 보조하 $\mathrm{draf} I \mathrm{IIb}$ 술기를 통해 비전두관을 개방하고 관찰되는 괴사 조직을 microdebrider와 드릴을 이용하여 모두 제거하였으 며 병리조직검사상 모균증으로 진단되었다(Fig. 4).

환자는 수술 후 면역억제제 조절을 위해 호흡기 내과로 전과 후 liposomal form의 IV amphotericin B(250 mg/day)를 수술 

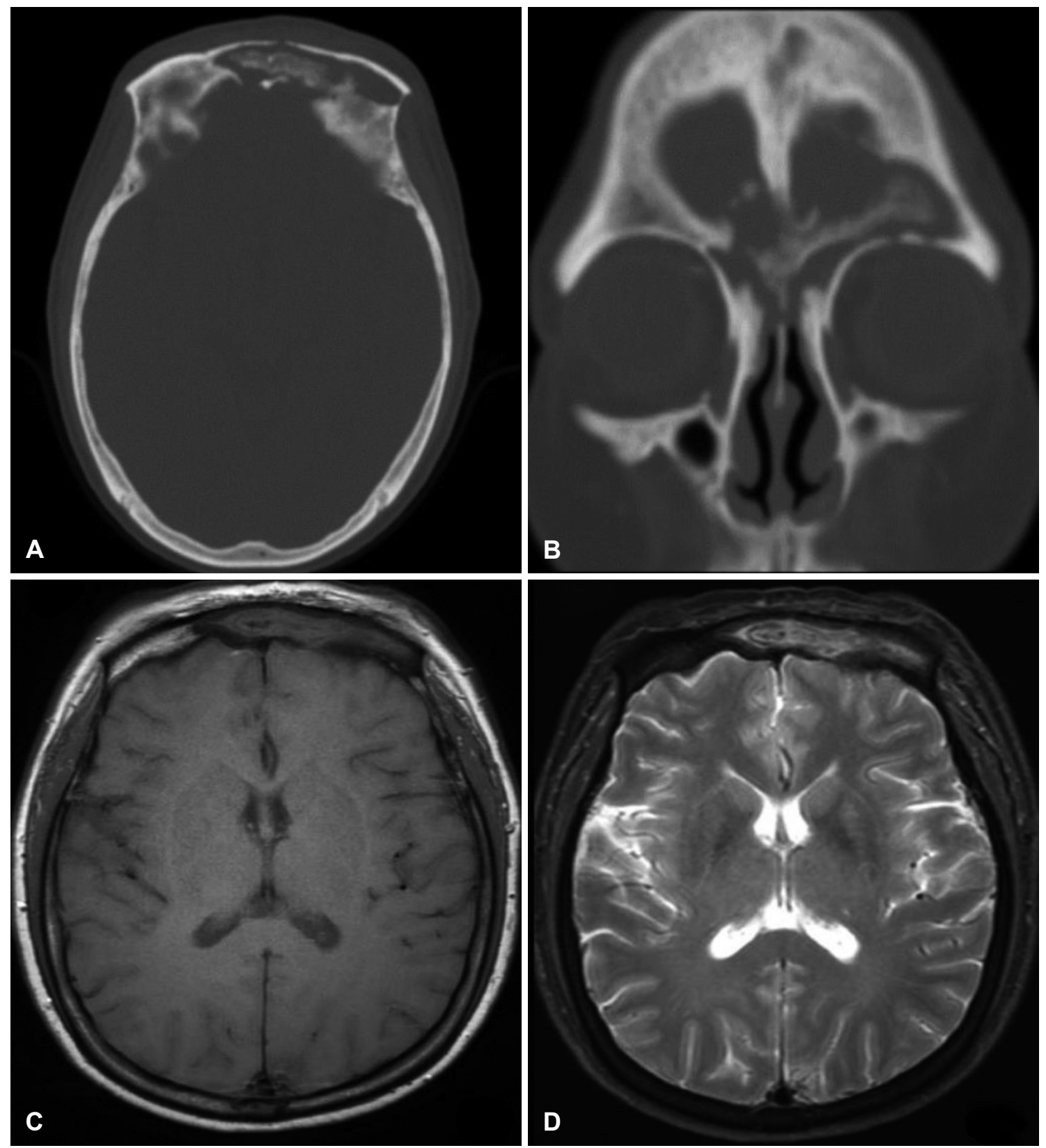

Fig. 3. Preoperative non-enhanced computed tomography (CT) scan and MRI of the frontal sinus lesion taken 13 months after lung transplantation. Axial (A) and coronal view (B) of CT scan show dense opacification and calcification with destruction of posterior wall of left frontal sinus. MRI shows low signal intensity on T1 weighted image (C) and heterogeneous signal intensity on T2 weighted image (D).

후 5주간 투여하였으며 퇴원 후 경구 항진균제만(posaconazole $300 \mathrm{mg} / \mathrm{day}) 10$ 일간 사용하였다.

수술 후 한 달째 시행한 CT 및 비내시경검사상 주위 점막 조직이 회복되고 있는 것을 확인하였다(Fig. 5A). 수술 1년 후부터 비침습적 형태의 곰팡이 덩어리가 관찰되었으나 드레 싱으로 쉽게 제거되었다(Fig. 5B). 현재 수술 후 18 개월까지 침습적인 곰팡이 감염증은 더 진행되지 않는 상태로 경과 관 찰 중이다(Fig. 5C and D).

\section{고 찰}

모균증은 식균작용이 감소한 면역저하 상태나 당뇨 환자 들에게 나타나는 기회감염이다. 급성형은 면역저하 상태의 환자들에게서 나타나 10 일 이내의 빠른 전개 및 높은 사망 률을 보이며 만성형은 낮은 레벨의 면역저하 상태에서 호발 하며 고전적으로는 4주 이상, 일부 연구에서는 7 개월 이상 지속되는 경증과 무통성 혹은 육아종성 병변을 이루고 석회 

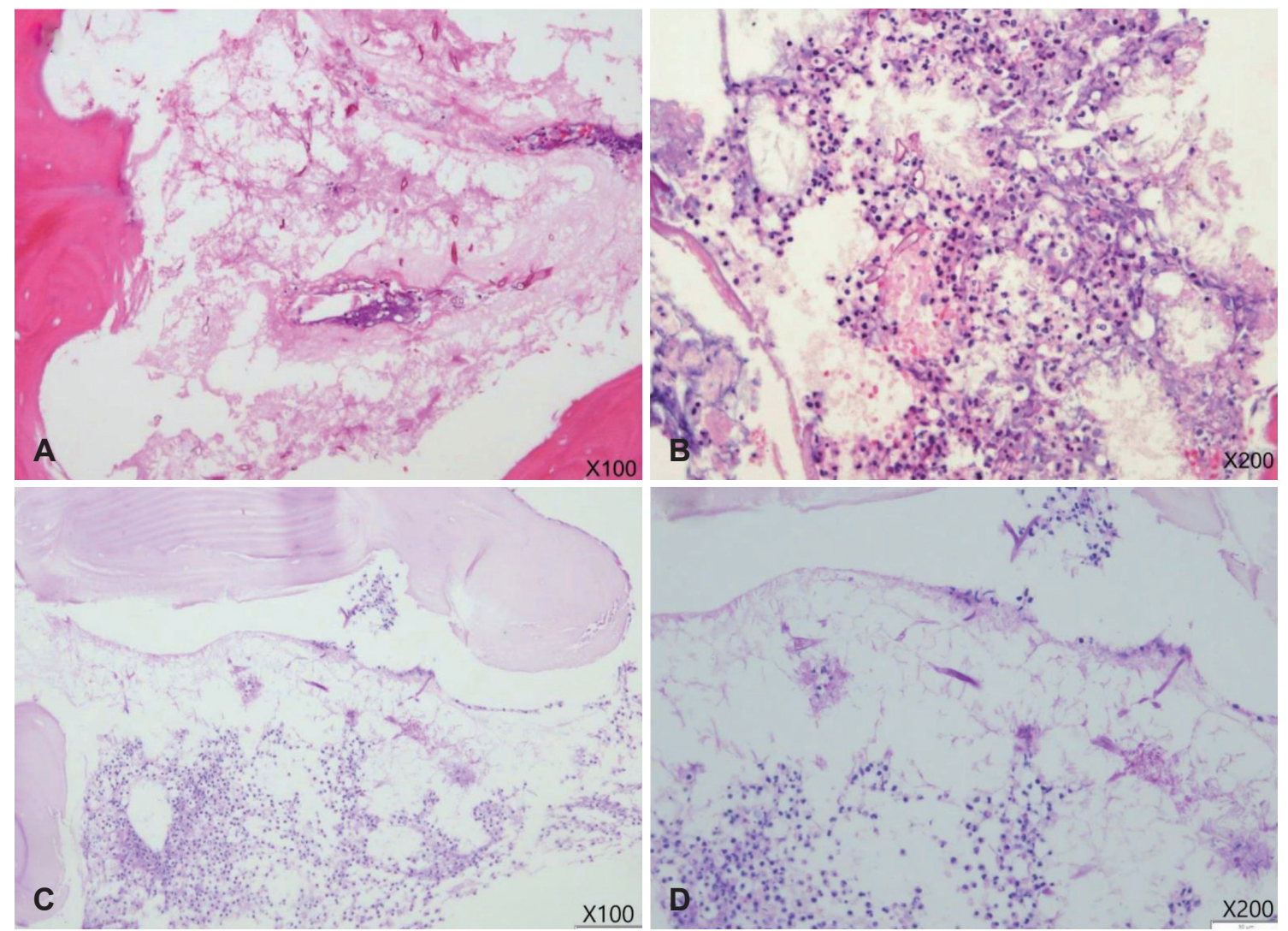

Fig. 4. Pathological specimen from left frontal sinus lesion shows invasive fungal hyphae without branch and septum, morphologically consistent with mucormycosis. Hematoxylin and eosin stain (A and B). Periodic acid-Schiff diastase stain (C and D).

화를 특징으로 한다.) 또한 모균증은 발생 장소에 따라서도 본 증례와 같이 더 치명적인 결과를 보일 수 있는 비-안와대뇌형 혹은 비뇌형(rhino-orbito-cerebral)과 비교적 좋은 예후를 보이는 비부비동형(sinonasal)으로 나눌 수 있다.) 만 성 비뇌모균증은 1960년대 이후로 PubMed에 약 22예만이 보고되고 있는 희귀한 질환이며 국내에서도 2016년에 한 증 례가 보고된 바 있으나 본 증례와는 다르게 장기 이식 및 면 역 억제제 복용력이 없었으며 내시경적 수술이 아닌 광범위 수술적 절제를 하였다.68)

모균증은 특히 조절되지 않는 당뇨와 케토산혈증의 유무 가 중요한데 이로 인해 중성구 감소 및 화학주성(chemotaxis)의 저해가 나타나 식균작용을 약화시키며 더 나아가 케토 산혈증은 혈청 철을 증가시켜 모균증의 진행을 가속화시키 기 때문이다. ${ }^{9}$ 본 증례의 경우 조절되지 않는 당뇨의 과거력 은 있었으나 명확한 케토산혈증은 없었다.

임상 양상은 대개 일반적인 부비동염 증상 및 안면통, 안와 부종, 발열, 혈성 비루 등이 먼저 나타나며, 첫 증상으로 안과 적 증상을 호소하는 경우가 가장 많다. ${ }^{10)}$ 병이 진행됨에 따라 안근마비, 안검하수, 안면신경마비 등이 발생할 수 있으며 만
성의 경우 해면정맥동 및 내경동맥 혈전증이 더 잘 일어난 다. ${ }^{11)}$ 그러나 비뇌모균증이 전두골의 골막하 농양을 일으키는 경우는 매우 드물며 국내에서는 두 번째 증례에 해당한다. ${ }^{12)}$

만성 비뇌모균증의 원인 균은 증례가 적어 Mucor ramosissimus, Rhizopus nigricans, Mucor irregularis 정도만이 확인되었으며, 모두 약 $36^{\circ} \mathrm{C}$ 이상의 체온과 유사한 온도에서 성장이 둔화되거나 멈추는 경향을 보여 이로 인해 비교적 느 린 진행 양상을 나타내는 것으로 유추할 수 있다. ${ }^{10,13)}$

이학적 검사상에서는 비강 및 부비동의 검은색 가피, 괴사 성 조직 소견 등이 확인된다. ${ }^{14)} \mathrm{CT}$ 소견상 골미란과 골파괴 및 석회화 소견이 나타날 수 있으며, MRI T1, T2 강조영상 모두에서 저신호 강도의 병변이 나타나는 경우가 많다. 따라 서 비특이적인 영상 소견만으로 만성 침습적 모균증과 악성 병변을 명확히 감별하는 것은 어려우므로 병리 진단이 확진 에 필수적이며 Grocott's methenamine silver-periodic acid Schiff, hematoxylin and eosin 염색을 통해 직각으로 가지 를 내는 격벽 없는 균사를 관찰할 수 있다. ${ }^{3)}$

$\mathrm{PPT}$ 는 전두골의 골막하농양을 의미하며 전두동의 염증 이 누공에 의해 파급되어 골수염 및 농양의 형성으로 이어진 

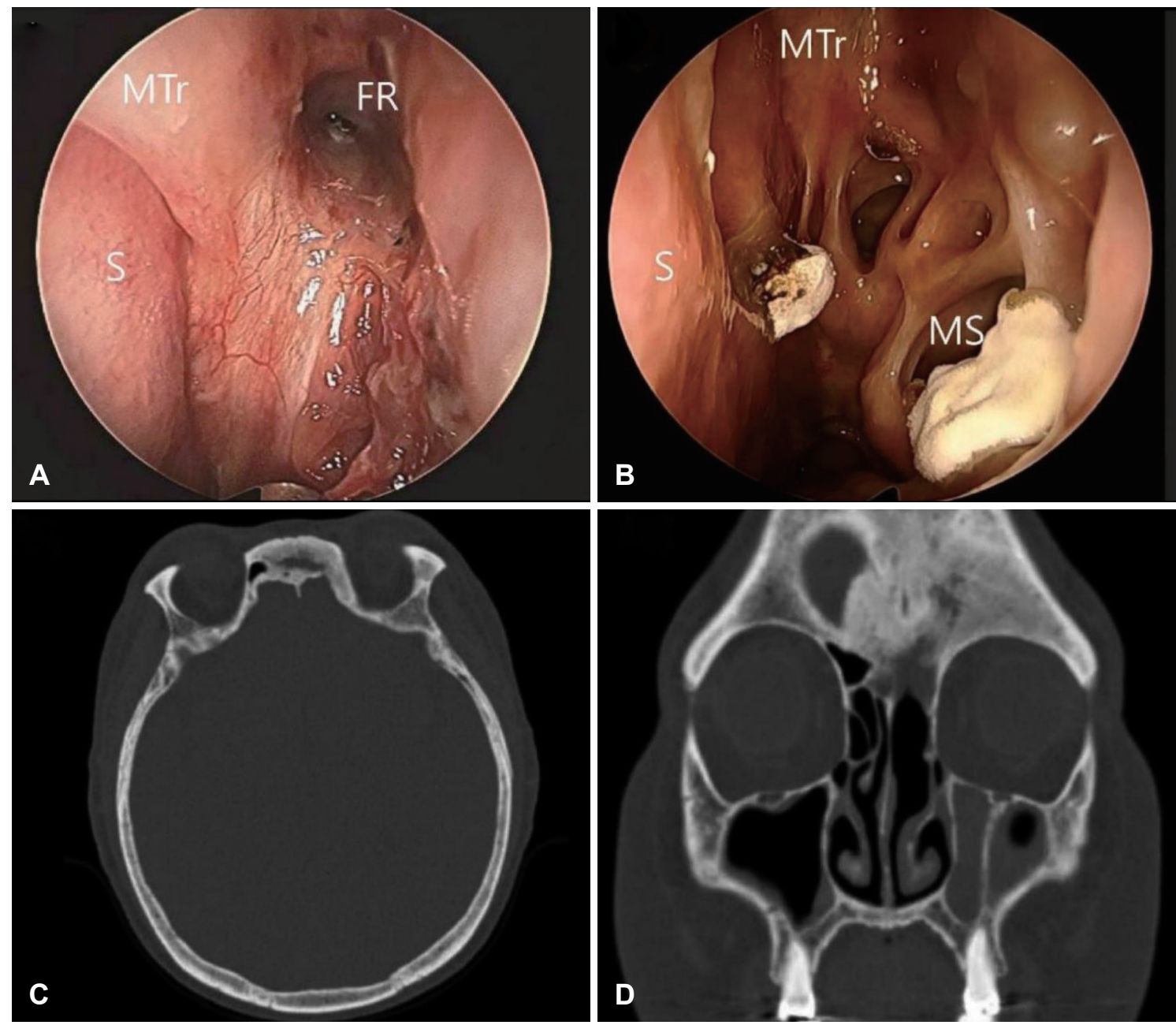

Fig. 5. Postoperative findings. Nasal endoscopic view (A) 1 month and (B) 18 months after the surgery. Morphologically non-invasive fungal content was noted 1 year after the surgery. However, there was no evidence of invasive fungal infection progression throughout postoperative computed tomography scans with the latest exam 18 months after the surgery (C and D). S, FR, MTr, and MS are labeled in endoscopic findings. S: septum, FR: frontal recess, MTr: middle turbinate remnant, MS: maxillary sinus.

다. 1768년 Percivall Pott에 의해 외상에 의한 것으로 처음 정의되었으나 이후 전두동 부비동염으로 인한 증례들도 보 고되었다. 완전히 발달되지 않은 전두동의 해부학적 구조나 아이들에게 흔한 판사이정맥의 혈류 증가로 인해 흔하게 발 병하여 성인에게서는 드물며 주로 10 20세에 흔하게 발병한 다. 전두골 통증, 두통, 안와 부종, 발열 등의 임상 증상이 있 으며 감염이 대뇌까지 파급될 시 뇌수막염, 경막외 농양, 뇌 농양으로 악화될 수 있다. 항생제 치료만으로는 보통 부적합 하며 대부분의 환자들은 수술적 배농을 같이 필요로 한다. ${ }^{15}$ 본 증례는 모균증에 의한 PPT의 경우로 내시경을 이용한 괴 사 조직의 절제, amphotericin $\mathrm{B}$ 의 투여, 기저질환의 교정 및 치료를 같이 실시하였다. ${ }^{4,14}$

본 증례에서는 이마에 돌출된 형태의 발적과 압통이 동반 된 종창과 안와부종을 첫 증상으로 내원한 환자가 폐이식
후 면역억제제 복용 및 조절되지 않는 당뇨 병력이 동반되었 으며, $\mathrm{PPT}$ 가 동반되었다는 점에서 기존의 증례들과 비교 시 의미가 있다. 치료 방법도 일반적인 두개안면절제술이 아닌 최근 대두되는 내시경을 이용한 draf IIb 방법과 항진균제 사용을 병용하였다.

\section{Acknowledgments}

None.

\section{Author Contribution}

Conceptualization: Hyung-Ju Cho, Jong-Gyun Ha. Data curation: Chan Lee, Sung-Eun Choi, Jong-Gyun Ha. Formal analysis: JongGyun Ha. Investigation: Chan Lee, Sung-Eun Choi. Methodology: Jong-Gyun Ha. Project administration: Hyung-Ju Cho, Jong-Gyun Ha. Resources: Hyung-Ju Cho. Supervision: Hyung-Ju Cho, JongGyun Ha. Validation: Hyung-Ju Cho, Jong-Gyun Ha. Visualization: Chan Lee, Sung-Eun Choi. Writing_original draft: Chan Lee. Writing — review \& editing: Jong-Gyun Ha. 


\section{ORCID}

Jong-Gyun Ha https://orcid.org/0000-0002-2712-1297

\section{REFERENCES}

1) Leitner C, Hoffmann J, Zerfowski M, Reinert S. Mucormycosis: Necrotizing soft tissue lesion of the face. J Oral Maxillofac Surg 2003;61(11):1354-8.

2) Roden MM, Zaoutis TE, Buchanan WL, Knudsen TA, Sarkisova TA, Schaufele RL, et al. Epidemiology and outcome of zygomycosis: A review of 929 reported cases. Clin Infect Dis 2005;41(5):634-53.

3) Jin YW, Kim KH, Cho JS, Cha CI. Rhinocerebral mucormycosis with selective cranial nerve palsy. Korean J OtorhinolaryngolHead Neck Surg 2001;44(6):674-7.

4) Do NY, Lee JH, Dong GW. Clinical study of rhinocerebral mucormycosis. Korean J Otorhinolaryngol-Head Neck Surg 2005;48(10):1228-34.

5) Lee SB, Yi JS, Kim JY, Chang C. Rhino-orbito-cerebral mucormycosis complicated as facial paralysis and ophthalmoplegia without rhinologic manifestation. Korean J Otorhinolaryngol-Head Neck Surg 2015;58(7):503-8.

6) Gutiérrez-Delgado EM, Treviño-González JL, Montemayor-Alatorre A, Ceceñas-Falcón LA, Ruiz-Holguín E, Andrade-Vázquez CJ, et al. Chronic rhino-orbito-cerebral mucormycosis: A case report and review of the literature. Ann Med Surg (Lond) 2016;6:87-91.

7) Peterson KL, Wang M, Canalis RF, Abemayor E. Rhinocerebral mucormycosis: Evolution of the disease and treatment options. Laryngoscope 1997;107(7):855-62.

8) Kim D, Kim J-w, Ahn S-J, Hong S-L. Chronic invasive sinonasal mucormycosis; A rare disease entity. J Rhinol 2016;23(2):119-23.

9) Spellberg B, Edwards J Jr, Ibrahim A. Novel perspectives on mucormycosis: Pathophysiology, presentation, and management. Clin Microbiol Rev 2005;18(3):556-69.

10) Dimaka K, Mallis A, Naxakis SS, Marangos M, Papadas TA, Stathas T, et al. Chronic rhinocerebral mucormycosis: A rare case report and review of the literature. Mycoses 2014;57(11):699-702.

11) Galetta SL, Wulc AE, Goldberg HI, Nichols CW, Glaser JS. Rhinocerebral mucormycosis: Management and survival after carotid occlusion. Ann Neurol 1990;28(1):103-7.

12) Yoon H, Jeon S-B, Kim HA, Kwon BS, Kim S-H, Kang JK. Rhinocerebral mucormycosis manifested as Pott's puffy tumor. J Neurocrit Care 2014;7(2):111-5.

13) Hemashettar BM, Patil RN, O'Donnell K, Chaturvedi V, Ren P, Padhye AA. Chronic rhinofacial mucormycosis caused by Mucor irregularis (rhizomucor variabilis) in India. J Clin Microbiol 2011;49(6):2372-5.

14) Vessely MB, Zitsch III RP, Estrem SA, Renner G. Atypical presentations of mucormycosis in the head and neck. Otolaryngol Head Neck Surg 1996;115(6):573-7.

15) Akiyama K, Karaki M, Mori N. Evaluation of adult Pott's puffy tumor: Our five cases and 27 literature cases. Laryngoscope 2012;122(11):2382-8. 